\title{
THE
}

\section{A Pilot Examination of Self-Esteem, Depression, and Sleep in College Women}

Jessica R. Conti

University of Rhode Island

Sue K. Adams

University of Rhode Island, suekadams@uri.edu

Tiffani S. Kisler

Univerisity of Rhode Island, tkisler@uri.edu

Follow this and additional works at: https://digitalcommons.uri.edu/hdf_facpubs

The University of Rhode Island Faculty have made this article openly available.

Please let us know how Open Access to this research benefits you.

This is a pre-publication author manuscript of the final, published article.

Terms of Use

This article is made available under the terms and conditions applicable towards Open Access Policy Articles, as set forth in our Terms of Use.

\section{Citation/Publisher Attribution}

Jessica R. Conti, Sue K. Adams \& Tiffani S. Kisler (2014) A Pilot Examinationof Self-Esteem, Depression, and Sleep in College Women, NASPA Journal About Women in HigherEducation, 7:1, 47-7. doi: 10.1515/ njawhe-2014-0004

Available at: http://dx.doi.org/10.1515/njawhe-2014-0004

This Article is brought to you for free and open access by the Human Development and Family Science at DigitalCommons@URI. It has been accepted for inclusion in Human Development and Family Science Faculty Publications by an authorized administrator of DigitalCommons@URI. For more information, please contact digitalcommons-group@uri.edu. 
An Examination of Self-Esteem, Depression, and Sleep in College Women

Jessica R. Powers, Sue K. Adams, Tiffani S. Kisler

University of Rhode Island 


\begin{abstract}
While sleep deficits in adulthood are common and worsening, college females experience significantly more sleep problems and depression than their male counterparts. In recent years, sleep has been investigated as one of the primary contributors to college functioning and GPA. No known study, however, has investigated the connection between self-esteem, depression and sleep. Questionnaire assessments were given to 42 female college juniors and seniors, including: demographic information, Rosenberg Self-esteem Scale, Beck Depression Inventory, and Pittsburg Quality Sleep Index. The current study investigates the relation between college selfesteem and sleep quality, as mediated by depression. The results of the study indicate that selfesteem predicts both depression and sleep quality, such that decreased levels of self-esteem are associated with higher levels of depression and decreased sleep quality. Moreover, depression also predicts sleep quality. Further, depression serves to mediate the relation between self-esteem and sleep quality. The results suggest that students' self-esteem plays a significant role in the experience of depression and that depression is the primary mechanism through which selfesteem influences sleep. College administrators should consider integrating self-esteem promotion strategies into their campus wide intervention efforts to promote mental health and academic success.
\end{abstract}




\section{Introduction}

While sleep deficits in adults are common and worsening, college students experience significantly more sleep problems than the general population. As many as $73 \%$ of college students report sleep problems and only 11\% of students feel well rested upon waking (Buboltz, Brown \& Soper, 2001). College-aged women are particularly vulnerable to sleep problems, reporting shorter duration of sleep and poorer sleep than their male peers (Buboltz et al, 2001). Females college students also experience earlier rise times, longer sleep latency, more awakening during the night and lower ratings of sleep quality measures as compared to their male counterparts (Tsai \& Li, 2004).

The college years are also a stressful time when students are not only striving for academic achievement but also navigating social relationships and entry into professional life. Students who experience difficulty coping with these various demands are frequently suffering from low self-esteem (Bettencourt, Charlton, Eubanks, Kernahan, \& Fuller, 1999). Further, college-aged females are particularly vulnerable, with females twice as likely to experience lower self-esteem and depressive symptoms as males (American Psychological Association [APA], 2000; Kelly, Kelly, Brown, \& Kelly, 1999). Depressive symptoms are also related to increased sleep problems (Buboltz et al, 2001). Therefore, it is important to understand the impact of these psychological factors on the important biological process of sleep, especially given the impact of sleep on the overall health and functioning of college females. 


\section{Depression and Sleep}

According to the American College Health Association's National College Health Assessment (ACHA-NCHA) (2005), the rate of depression among college students has been on the rise with $14.9 \%$ of students reporting having ever been diagnosed with depression. Notably, females appear to experience low self-esteem and more depression and somatization of symptoms than men (Kelly et al, 1999; Nolen-Hoeksema, 2001). Women, however, tend to underutilize therapeutic interventions targeted at improving depressive symptoms, with only $1 / 3$ of women receiving the treatment they need (NAMI, 2009). One in five students experience depression in high school, and half of these students will relapse in early adulthood (Lewinsohn, Rohde, Klein, \& Seeley, 1999). The four most commonly cited reasons for students' depression are academic and economic problems, loneliness, and relationship difficulties (Furr, Westefeld, McConnell, \& Jenkins, 2001).

There is also a fair amount of evidence to suggest that impaired sleep in college is a major contributor to depressed mood (Scott, McNaughton, \& Polman, 2006; Thacher, 2008).

Individuals with depression have reported poorer overall sleep quantity as well as quality (Gupta, Dahiya, \& Singh Bhatia, 2009). With regard to sleep quality, individuals who are clinically depressed often report more difficulty falling asleep than nonclinical populations (Koffel \& Watson, 2009). Once asleep, they also report difficulties staying asleep or poorer overall sleep quality upon waking (Gupta et al, 2009; Howell, 2008; Zhang \& Diao, 2006). Individuals who are depressed also report lesser total sleep time, more sleep awakenings, earlier wake time, and taking longer to fall asleep and to get out of bed (Gupta et al, 2009). Conversely, difficulty initiating and maintaining sleep, poor overall sleep quality and lassitude (i.e., lack of energy) 
have been shown to increased depression in college-aged students and adolescents (Koffel \& Watson, 2009; Johnson, Roth, \& Breslau, 2006). It is clear that impaired sleep has been linked to an array of issues including difficulty focusing, impaired consolidation information into longterm memory, decreased cognitive functioning and lower GPA (Buboltz et al, 2001; Howell, 2008; Pilcher \& Walters, 1997; Spoormaker \& van den Bout, 2005; Scott, McNaughton, \& Polman, 2006; Trockel, Barnes, \& Egget, 2000; Zhang \& Diao, 2006; Johnson, Roth, \& Breslau, 2006).

\section{Self-esteem}

According to Adler's Self-esteem Theory, individuals experience themselves as having an intrinsic value and constantly try to increase that value. Self-esteem or self-worth is a significant favor in successfully negotiating both personal and social stressors functioning psychologically, emotionally, socially, and academically (Bettencourt \& Dorr, 1997; Bettencourt et al, 1999). The college years are a period of accelerated identity development, which can pose new challenges for developing and maintaining healthy self-esteem (Meeus, Iedema, Helsen, and Vollebergh (1999). Students who have difficulty with this process can suffer from lessened self-esteem and self-doubt, loneliness, and depression (Lewinsohn, Rohde, \& Seeley, 1998). Assessing and supporting the development and improvement of self-esteem could potentially have a significant impact on a college students' personal happiness and overall physical and mental health, both in the short and long term as they navigate making personal choices about their life as adults. 
With regards to the college student females, the literature on self-esteem is broad and varied. It has been well documented that females experience both lower rates of self-esteem and higher rates of depression than their male peers (Kelly et al, 1999; Nolen-Hoeksema, 2001, Garaigordobil, Perez, \& Mozaz, 2008). While college students’ self-esteem has been wellresearched, studies have tended to focus on self-esteem in relation to specific variables, such as college adjustment and residence halls (Bettencourt et al, 1999), perceived academic abilities

(Torres, Zenner, Benson, Harris, Koberlein, 2007), gender and body image (Pilafova, Angelone, Bledsoe, 2007), social support (Williams, \& Galliher, 2006), depression (Hayes, Harris, \& Carver, 2004), emotion, mood and personality (Oosterwegel, Field, Hart, Anderson, 2001), and psychological health (Macinnes, 2006). The associations, however, between self-esteem and sleep in females have not been examined in previous research and therefore are a worthy area of further examination.

\section{Depression and Self-esteem}

Beck (1967) found that negative self-assessments may be a causal determinant of depression. Individuals at risk for depression often struggle with thoughts about their own self-worth (Wenzlaff \& Bates, 1998). Researchers have also shown that while low self-esteem contributes to subsequent levels of depression, depression is not predictive of low self-esteem (Orth, Robines, Trzesniewski, Maes, \& Schmi, 2009; Trzesniewski, 2004; Lewisohn et al, 1981).

In a cross-cultural regression analysis of two longitudinal studies (one from the U.S. and one from Germany), researchers explored the direction of correlation between self-esteem and depression during adulthood (Orth et al, 2009). Low self-esteem was found to be a risk factor for 
depressive symptoms at all stages of the life span (Orth et al, 2009). Trends for self-esteem were both age and culturally independent. Another study by Trzesniewski (2003) found that low selfesteem is unstable in childhood and older adulthood, but stable during young adulthood. During this static time, students with low self-esteem may especially need support when they seek mental health counseling for depressive symptoms (Trzesniewski, 2003).

\section{The Current Study}

To summarize, college women are especially vulnerable to suffering from feelings of low selfesteem. There is a significant gap in the literature of studies examining the importance of selfesteem in female college students, particularly how self-esteem relates to depression and sleep. Although depression and self-esteem, and depression and sleep, are clearly interrelated, the connection between self-esteem and sleep is less evident. Increased stress and internal turmoil due to poor self-esteem may then contribute to poorer sleep quality as individuals may lack the ability and strategies necessary to relax and fall into and maintain sound sleep.

The current study will be guided by Chickering's Seven Vector Theory of Student Development (Chickering, 1993). Specifically, Vector 2 "Managing emotions" will frame the examination of how self-esteem influences depression and sleep. The current study posits the following hypotheses: 1) decreased self-esteem will predict poorer sleep quality, 2) poorer self-esteem will predict more depressive symptoms, 3) more depressive symptoms will predict poorer sleep quality, and 4) self-esteem and sleep quality will be mediated by depression, such that the presence of depression will explain the relation between self esteem and poorer sleep quality. The proposed model of these relations is depicted in Figure 1. [Insert Figure 1 here] 


\section{Method}

\section{Design and Procedures}

The data for this study was drawn from a larger study examining the effects of sleep disturbance on multiple mental health and academic indicators, including depressive symptoms, anxiety, alcohol use and academic achievement. Data for the larger study was collected from juniors and seniors at a medium-sized state university between 2008 and 2010. The complete research study took approximately 20 minutes to complete and all participants earned extra credit toward a final exam for their participation in the study. An alternate extra credit assignment was offered in the case that students did not feel comfortable participating in the study. All data collection procedures were conducted in accordance with the Institutional Review Board regulations at the principal investigator's university.

\section{Participants}

The current study recruited students during one semester of study. A total of 42 female students completed the self-esteem measure for inclusion in the principal investigator's master's thesis. The majority of participants from this sample self-identified as White (97.6\%) and $2.4 \%$ selfidentified as Multiracial, 2\%. Age ranged from 20 to 30, with a mean of 21 (SD=1.59). Regarding grade level, $88.1 \%$ of the participants were seniors, $7.1 \%$ were juniors, and $4.8 \%$ were non-matriculating. Of the 42 participants, 6 identified themselves as being student athletes. Students were also asked about current sleeping arrangements. The majority of participants $(85.7 \%)$ reported sleeping in a room alone, and $14.3 \%$ sleeping in a room with one other person. 


\section{Measures}

The research study included a total of six measures. Participants were first asked to complete a demographic questionnaire, identifying relevant information including age, gender, racial/ethnic background, and living arrangements, etc. The following measures were used to assess primary study variables.

\section{Self Esteem}

The Rosenberg Self-Esteem Scale was used to assess students' level of self-esteem. The measure is a 10 item Likert-scale, with answers on a four-point scale from strongly agrees to disagree (Rosenberg, 1965). Sample items include, "I feel that I am a person of worth, at least on an equal plane with others," "All in all, I am inclined to feel that I am a failure," and, "I wish I could have more respect for myself." Possible scores range from 0 to 30 , with higher scores being indicative of higher self-esteem. The scale is a widely-used measure for assessing self-esteem, with a twoweek, test-retest coefficient of 0.85 . Internal consistency for the current study was .90 .

\section{Depression}

Depressive symptoms were measured using the Beck Depression Inventory-II (BDI-II), a widely used measure comprised of 21 items scored on a Likert scale (Beck, Brown, \& Steer, 1996). The BDI-II has high internal consistency (alpha $=0.91$, test-retest $=0.93$ ). Individuals chose one statement out of four, rated 0-3, which best describes the way they have been feeling in the last week. For example, on happiness: "0-I get as much satisfaction out of things as I used to, 1-I don't enjoy things the way I used to, 2-I don't get real satisfaction out of anything anymore, 3-I am dissatisfied or bored with everything." Scores on the BDI-II range from 0-63 and indicate 
varying levels of depression: 0-13 minimal, 14-19 mild, 20-28 moderate, and 29-63 severe. Internal consistency for the current sample was .89 .

Sleep

The Pittsburgh Sleep Quality Index (PSQI) was used to assess sleep quality (Buysse, Reynolds III, Monk, Berman, \& Kupfe, 1989). The PSQI is a 19 item self-report measure that assesses quality of sleep and sleep disturbances during the past month. Internal consistency for this measure has been reported at alpha $=0.83$. Sample items include, "During the past month, what time have you usually gone to bed at night," and "how many hours of actual sleep did you get at night?" The remaining questions ask the individual to check the time frame that best describes their sleep disturbances, from "not during the past month" to "three or more times a week." While total score on the PSQI ranges from 0 to 21, scores greater than five are suggestive of significant sleep disturbances.

Results

The present study examined 1) the direct associations between self-esteem, depression, and sleep symptoms and 2) if depressive symptoms mediate the effect of self-esteem on sleep quality.

\section{Preliminary Analyses}

Primary study variables (i.e., self-esteem, depression, and sleep quality) were investigated for missing data. In the case of missing items, the group mean for that item was substituted. Since no individual was missing more than one score, all participants were included in the analyses. 
In addition, skewness and kurtosis were examined in the primary study variables to assess both the asymmetry and the peakedness of the probability distribution respectively. While results were all within an acceptable range, the skewness and kurtosis of depression were outside of the recommended -1 to 1 range. Therefore, as a precursor to conducting multiple regression analyses, z-scores were calculated for sleep, depression, and self-esteem in order to standardize the means of each variable. These z-scores were entered into three sets of multiple regressions to test the study hypotheses. The means and standard deviations of the primary study variables are presented in Table 1. Post hoc power analysis revealed that the current power was 0.99 .

Characteristics of the data were also examined. Analysis of the primary study variables of selfesteem, depression, and sleep revealed a normal distribution for each, with no outliers. Next, issues of multicollinearity were assessed. A correlation matrix was computed to examine the correlations among independent variables (see Table 2).

\section{Primary Analyses}

For the primary analyses, a series of Ordinary Least Square (OLS) regressions were conducted to investigate the relation of self-esteem to sleep quality, self-esteem to depression, and depression to sleep quality (see Table 3). As predicted, Hypothesis 1 was supported. Specifically, an OLS regression analysis revealed that among college students, self esteem predicted sleep quality ( $\beta=$ $-.295, \mathrm{p}<.001)$. Moreover, self-esteem explained $39.9 \%$ of the variance in sleep quality, $\mathrm{F}(1$, $40)=25.86, \mathrm{p}<.001$. Hypothesis 2 was also confirmed for self-esteem predicted depression $(\beta=-$ .973 , $\mathrm{p}<.001$. Self-esteem explained $55.1 \%$ of the variance in depression, $\mathrm{F}(1,41)=48.99, \mathrm{p}<.001$, indicating that lower levels of self-esteem is related to higher levels of depression. Similarly, 
Hypothesis 3 was supported as depression predicted sleep quality, $(\beta=.245, \mathrm{p}<.001$. Depression explained $46.6 \%$ of the variance in sleep quality, $\mathrm{F}(1,40)=34.08, p<.001$.

\section{Secondary Analyses}

Following the primary analyses a mediation analysis was conducted to examine the relation between self-esteem and sleep quality with depression as a mediator. The most widely used approach for evaluating mediating effects is the four-step causal model suggested by Kenny and colleagues (Baron \& Kenny, 1986). In a Monte Carlo study, however, it was demonstrated that in some cases the four-step causal model had lower power than the product of coefficients tests; the product of coefficients test also has accurate Type 1 error rates (MacKinnon, Lockwood, Hoffman, West, \& Sheets, 2002). Therefore, mediation analyses were conducted according to Mackinnon and colleagues' (1998) distribution of product method. As predicted, Hypothesis 4 was confirmed as depression fully mediated the relation between self-esteem and sleep quality, $\beta$ $=.171, p<.001$ (see Figure 2). [Insert Figure 2 here]

\section{Conclusion}

This study aimed to examine the influence of self-esteem and depression on sleep in female college students. The findings of the study suggest that self-esteem predicts depression and sleep quality and depression predicts sleep quality. Moreover, depression mediated the relation between self-esteem and sleep quality, demonstrating that depression is the primary mechanism through which self-esteem influences sleep among college females. 
Social connectedness has surfaced as a predictor of depression and self-esteem among college students (Williams \& Galliher, 2006; Bosacki, Dane \& Marini, 2007). In an effort to counterbalance feelings of low self-esteem and depression, foster more positive social relationships and improve one's level of self-esteem, college students may be sacrificing their sleep in order to stay in touch with peers throughout the night. In turn, these sacrifices for social connection are then influencing their overall sleep quality. In fact, this is consistent with results from a previous study which found that students who had higher levels of texting and phone use at night also reported poorer sleep quality and depression (Adams, Kisler, Andrew, Medeiros, Brooks, Vacca, \& Cummings, 2010). Thus it appears that students may be delaying the onset of sleep to connect with peers and also wake up during the night to answer text messages. A students' inability to separate from peers during sleep may lead to engaging in technological distractions. These distractions may be major factors in student's impaired sleep and negative mood. Many strategies that college students employ to promote self-esteem and happiness may be contributing to their report of sleep difficulties. Given the chronicity of both self-esteem and some sleep problems, it is important to identify that future research identify the associations among these variables.

\section{Implications for Intervention}

College students are more likely to seek clinical care for depressive symptoms and sleep problems than for issues with low self-esteem. In theses instances, interventions targeted toward identifying students who display clear signs of fatigue, struggle academically despite outwardly seeming competent, are frequently late to or miss class, appear tired and have difficulty concentrating during lectures may be beneficial. This direction of intervention is particularly 
important for in college settings, medications are traditionally prescribed to treat sleep problems (Fortuna et al., 2010), however, sleep medications would be unlikely to impact one's experience of depression or low self-esteem. Thus, intervention efforts would be entering at the wrong level and as a result may be unsuccessful in treating the issues at hand.

Moreover, based on the predictive relation found between depression and sleep, treating the psychological nature of depression will also have positive implications for sleep quality. When depression, however, is treated without incorporating self-esteem, the underlying negative belief systems that influence negative cognitive schemas may not be adequately addressed. Therefore, interventions aimed at improving self-esteem may lead to individuals having a better sense of personal value and happiness. This could translate into individuals viewing themselves as more capable and worthy, which serves as a protective factor in dealing with stressors across a variety of domains including physiologically, psychologically, emotionally, and socially (Friedlander et al., 2007). Contrastingly, individuals who maintain lower levels of self-esteem may not experience themselves as valuable. Fostering and improving individual self-esteem could have considerable influence in both psychological and physical domains, as belief systems about the self guide all decision-making processes such as self-care (i.e., sleep hygiene). Since self-esteem is malleable in childhood, prevention efforts should target improving self-esteem in young girls, therefore affecting both depression and sleep in later development (Trzesniewski, 2003).

\section{Study Limitations}

There are a number of limitations in the current study. First, the study sample was small and relatively homogenous; this limits both the ability to generalize results to other populations and 
the statistical power to detect significant relations between sample demographics and primary study variables. Second, while extensive research found trends that led to this study's model and direction of causality, it is impossible to control reciprocal influence using this methodological design. It is reasonable to assume that individuals who are sleep deprived are at higher risk for depression. Additionally, individuals experiencing higher levels of fatigue and negative affect would be more likely to rate their self-esteem as lower because previous research has shown that individuals experiencing poor sleep generally have a more negative affect and report lower life satisfaction (Kelly, 2004; Pilcher \& Walters, 1997).

Measurement of self-esteem is also a limitation of the present study. Based on Adler's selfesteem research, this study sought to theorize self-esteem as the incongruity created between an individual's feelings of self-worth and the ideal "set point" they were striving for. However, such an assessment tool for measuring self-esteem could not currently be found. Rosenberg was thus chosen for its reputation as the standard against which new measures are evaluated and for its ecology of time. Future studies may want to consider different methods to operationalize selfesteem and whether using more specific domain-related measures, such as Harter's Self Perception Profile, is a more appropriate measure, particularly for women.

Perhaps the most considerable conceptual concern was the similarity found in the literature between the predictor variable of self-esteem and the mediating variable of depression. Many definitions of self-esteem include the experience of depression and vice versa. This study, however, found considerable evidence that the two are separate constructs, and were treated accordingly. While self-esteem is an individual's appraisal of personal self-worth based on 
experience, depression is a negative viewpoint about the world based on cognitive schema. Additionally, depression is generally considered to be a psychological condition involving sadness and withdrawal, whereas self-esteem may involve no affect whatsoever.

Depression is a strikingly different experience that occurs when a person identifies with his or her thoughts and emotions, resulting in suffering both physically and emotionally. The statement "I am depressed," is significant, literally (and inaccurately) defining someone as the emotive state. A person may be experiencing depression, but this is not an inalterable state of being. If an individual can make this distinction, it is easy to see how self-esteem and depression operate independently of one another. Here are two examples: a construction worker may be depressed that he was recently laid off but, because he has high self-esteem, he sees himself as having an internal locus of control and actively looks for how he can get back into the job market. Another woman may have incredibly low self-esteem and self-image regarding her body and her intellectual capabilities, but she still enjoys her job and has a solid network of social support, which serve as protective factors from depression (Friedlander et al., 2007).

\section{Future Directions}

Future studies would benefit from larger and less homogenous samples when evaluating the relation between self-esteem and depression, the interconnectedness of these constructs, and how best to operationalize them in research. College administrators, clinicians, and researchers should further explore the therapeutic role of self-esteem as it relates to depression, as well as whether or not this relation differs between genders. To improve validity, future studies should consider using multiple methods of assessing self-esteem and depression beyond self-report, possibly 
including spousal/peer or researcher observations. As self-esteem was directly associated with depression, it appears that the influence it can indirectly have on sleep and other potential areas of psychological and physical functioning would illuminate self-esteem as a valuable construct to continue measuring, above and beyond depression. If individuals' increased sense of self esteem simultaneously increases personal happiness and sleep quality, the implications for life satisfaction may be significant.

\section{Conclusions and Implications for Women in Higher Education}

Sleep difficulties are prevalent in the college population, particularly in females, and have been previously shown to negatively influence functioning both emotionally and academically. When sleep problems arise, depression is frequently investigated as the problem catalyst. Instead of treating depression alone, the findings from this study highlight the potential value in assessing and treating self-esteem, which may influence both psychological and physical functioning as it is mediated by depression. As the basis of self-knowledge, it is logical that low self-esteem is associated with and supports the negative cognitive schemas that construct depression. By examining and intervening in self-esteem as a predictor of depression, enhancing individuals' sense of personal value can have significant influence on the treatment and remission of depressive and subsequent sleep symptoms. In addition, promoting self-esteem could also help college women in their academic development. As proposed by Chickering's Seven Vector Theory of Student Development, helping a student to learn to better manage their emotions is an integral component to achieving academic success (Chickering, 1993). 
All too often college women suffer in silence from feelings of low self-worth. These feelings of negative self-evaluation may bring women into mental health treatment, but more often than not women are tasked to cope with their distress in isolation. Although all college students are in the process of forming their personal and professional identities, college women are particularly vulnerable to psychological and physical problems that may stem from their negative beliefs about themselves. It is our hope that college administrators and faculty consider the importance of promoting self-esteem among women, as our findings indicate that self-esteem is related to various domains of functioning. Helping to increase a student's self-esteem could take on many different forms, ranging from campus-wide interventions that encourage the development of “strong, professional women" to individual remarks from faculty members identifying a student's particular strength. We encourage college administrators, faculty and staff to consider what they can do to strengthen the self-esteem of the college women they encounter. Supportive exchanges could ultimately make a significant difference in the psychological and physical health of college women. 
Figure 1. Proposed relations among primary study variables.

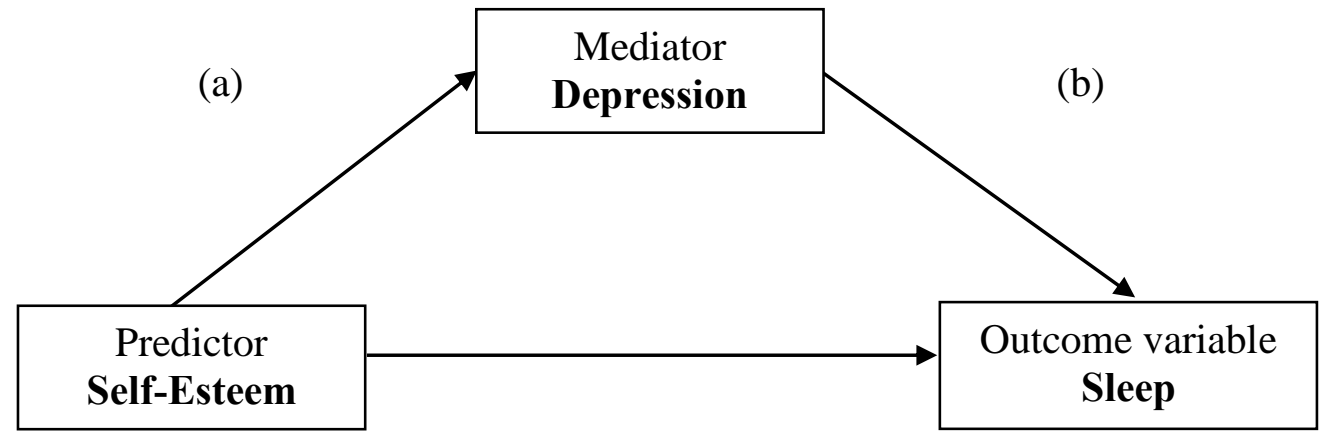

(c) 
Figure 2. Mediational effect of depression on sleep quality.

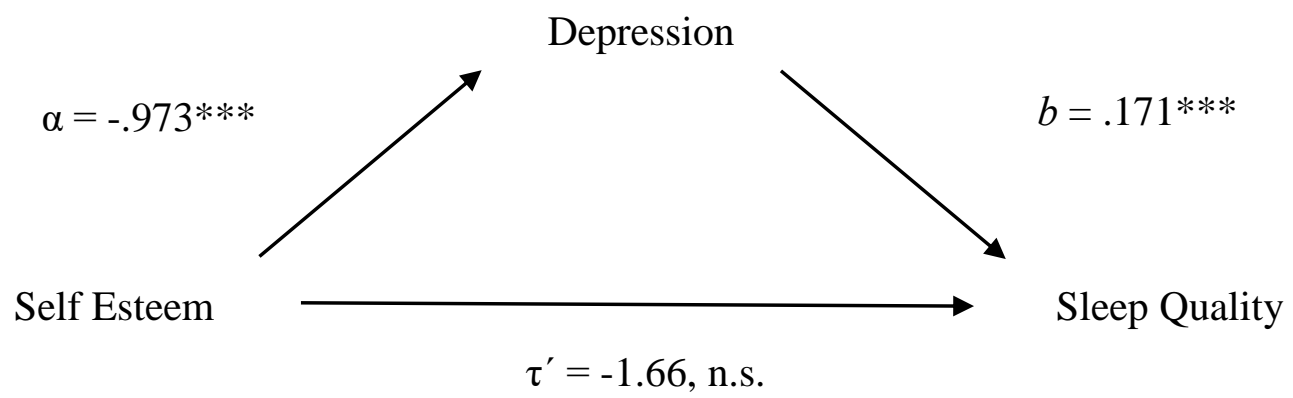

*All coefficients are unstandardized in accordance with the procedures of the product of coefficients mediation tests (MacKinnon et al., 2002). 
Table 1. Descriptive data for study variables.

\begin{tabular}{lccccc} 
Total Scores & $\underline{\text { Mean }}$ & $\underline{\text { SD }}$ & $\underline{\text { Items }}$ & $\begin{array}{c}\text { Potential } \\
\text { Range }\end{array}$ & $\begin{array}{c}\text { Actual } \\
\text { Range }\end{array}$ \\
Self Esteem $^{1}$ & 22.26 & 5.88 & 10 & $0-30$ & $11-30$ \\
Depression $^{2}$ & 10.52 & 7.71 & 21 & $0-63$ & $2-35$ \\
Sleep $^{3}$ & 8.34 & 2.76 & 19 & $0-21$ & $4-15$ \\
\hline
\end{tabular}

${ }^{1}$ Rosenberg Self Esteem Scale

${ }^{2}$ Beck Depression Inventory

${ }^{3}$ Pittsburg Sleep Quality Index 
Table 2. Significant Bivariate Correlations of Primary Study Variables

\begin{tabular}{|c|c|c|c|c|c|c|c|}
\hline 1. & 2. & 3. & 4. & 5. & 6. & 7. & 8. \\
\hline 1. Age & .064 & .160 & .136 & -.167 & .171 & .218 & -.206 \\
\hline 2. Ethnicity/Race & - & .011 & -.064 & -.064 & -.072 & -.020 & .127 \\
\hline $\begin{array}{l}\text { 3. Current } \\
\text { Class Standing }\end{array}$ & & - & .028 & -.367 & -.231 & -.274 & .170 \\
\hline $\begin{array}{l}\text { 4. Current } \\
\text { Sleeping } \\
\text { Arrangements }\end{array}$ & & & - & -.167 & -.216 & -.330 & .181 \\
\hline $\begin{array}{l}\text { 5. Student } \\
\text { Athlete }\end{array}$ & & & & - & .061 & -.128 & .017 \\
\hline $\begin{array}{l}\text { 6. Depression } \\
\text { Total Score }\end{array}$ & & & & & - & $.683 * *$ & $-.742 * *$ \\
\hline $\begin{array}{l}\text { 7. Sleep } \\
\text { Total Score }\end{array}$ & & & & & & - & $-.631 * *$ \\
\hline $\begin{array}{l}\text { 8. Self-Esteem } \\
\text { Total Score }\end{array}$ & & & & & & & - \\
\hline
\end{tabular}

Demographic variables, including age, and sleeping arrangements, were not related to the primary study variables. Therefore it was not necessary to control for these variables in the analyses. 
Table 3. OLS Regression Analyses ( $\mathrm{N}=236)$

Predictor

SE

$\beta$

$\mathrm{R}^{2}$

F

$\mathrm{p}$

I. Self-esteem

.058

$-.295$

.399

25.86

$.001 * * *$

II. Self-esteem

.139

$-.973$

.551

48.99

$.001 * * *$

III. Depression

.042

.245

.466

34.08

$.001 * * *$

Note. $p<.01^{* *} p<.001^{* * *}$

I: Self-esteem as a predictor of Sleep Quality

Dependent variable $=$ Pittsburg Sleep Quality Index

II: Self-esteem as a predictor of Depression

Dependent variable $=$ Beck Depression Inventory

III: Depression as a predictor of Sleep Quality

Dependent variable $=$ Pittsburg Sleep Quality Index 


\section{References}

ACHA-NCHA. (2005). Depression is up among college students. Brown University Child \& Adolescent Psychopharmacology Update, 7(2), 8.

Adams, S., Kisler, T., Andrew, L., Medeiros, T., Brooks, A., Vacca, A., \& Cummings, L. (2010, October).Text messaging and phone use during sleep: The impact on psychological well-being. Poster session presented at the annual meeting of the New England Psychological Association, Colchester, VT.

American Psychiatric Association. (2000). Diagnostic and statistical manual of mental disorders ( $4^{\text {th }}$ ed.). Washington, DC: Author.

Baron, R. M., \& Kenny, D. A. (1986). The moderator-mediator distinction in social psychological research: Conceptual, strategic, and statistical considerations. Journal of Personality and Social Psychology, 51, 1173-1182.

Beck, A.T. (1967). Depression: Clinical, experimental, and theoretical aspects. New York: Harper \& Row.

Beck, A. T., Brown, G., \& Steer, R. A. (1996). Beck Depression Inventory II manual. San Antonio, TX: The Psychological Corporation.

Bettencourt, B. A., \& Dorr, N. (1997). Collective self-esteem as a mediator of the relationship between allocentrism and subjective well-being. Personality and Social Psychology Bulletin, 23, 963-972.

Bettencourt, B.A., Charlton, K., Eubanks, J., Kernahan, C, \& Fuller, B. (1999). Development of collective self-esteem among students: Predicting adjustment to college. Basic and Applied Social Psychology, 2(3), 213-222.

Bosacki, S., Dane, A., Zopito, M. (2007). Peer relationships and internalizing problems in 
adolescents: Mediating role of self-esteem. Emotional \& Behavioural Difficulties, 12(4), 261-282.

Buboltz, W. C., Jr., Brown, F., \& Soper, B. (2001). Sleep habits and patterns of college students: A preliminary study. Journal of American College Health, 50(3), 131135.

Buysse, D.J., Reynolds III, C.F., Monk, T.H., Berman, S.R., \& Kupfer, D.J. (1989).

The Pittsburgh Sleep Quality Index: a new instrument for psychiatric practice and research. Psychiatric Research, 28(2), 193-213.

Chickering A.W. \& Reisser L. (1993). Education and identity. 2nd ed. San Francisco: Jossey-Bass.

Fortuna, R.J., Robbins, B.W., Caiola, E., Joynt, M., \& Halterman, J.S. (2010). Prescribing of controlled medications to adolescents and young adults in the United Stated. Pediatrics, 126(6), 1108-1116.

Friedlander, L.J., Reid, G.J., Shupak, N., \& Cribbie, R. (2007). Social support, self-esteem, and stress as predictors of adjustment among first-year undergraduates. Journal of College Student Development, 48(3), 259-274.

Furr, S. R., Westefeld, J. S., McConnell, G. N., \& Jenkins, J. M. (2001). Suicide and depression among college students: A decade later. Professional Psychology: Research and Practice, 32, 97-100.

Garaigordobil, M., Perez, J.I., Mozaz, M. (2008). Self-concept, self-esteem and psychopathological symptoms. Psicothema, 20 (1), 114-123.

Gupta, R., Dahiya, S., Singh Bhatia, M. (2009). Effect of depression on sleep: Qualitative or quantitative? Indian Journal of Psychology, 51 (2), 117-121. 
Hayes, A.M., Harris, M.S., Carver, C.S. (2004). Predictors of self-esteem variability. Cognitive Therapy and Research, 28(3), 369-385.

Howell, A. J., Digdon, N. L., Buro, K., \& Sheptycki, A. R. (2008). Relations among mindfulness, well-being, and sleep. Personality and Individual Differences, 45(8), 773777.

Johnson, E. O., Roth, T., \& Breslau, N. (2006). The association of insomnia with anxiety disorders and depression: Exploration of the direction of risk. Journal of Psychiatric Research, 40(8), 700-708.

Kelly, W. E. (2004). Sleep-length and life satisfaction in a college student sample. College Student Journal, 38(3), 428-430.

Kelly, W.E., Kelly, K.E., Brown, F.C., Kelly, H.B. (1999). Gender differences in depression among college students: A multi-cultural perspective. College Student Journal, 33(1), 72.

Koffel, E. \& Watson, D. (2009) The Two-factor structure of sleep somplaints and its relation to depression and anxiety. Journal of Abnormal Psychology, 118(1) 183-194.

Lewisohn, P.M., Steinmetz, J.L., Larson, D.W., \& Franklin, J. (1981). Depressionrelated cognitions: Antecedent or consequence? Journal of Abnormal Psychology, 90, 213-219.

Lewinsohn, P.M., Rohde, P., Klein, D.N., \& Seeley, J.R. (1999). Natural course of adolescent major depressive disorder. Journal of the American Academy of Child and Adolescent Psychiatry, 38, 56-63.

Lewinsohn, P.M., Rohde, P., \& Seeley, J.R. (1998). Major depression in older adolescents: Prevalence, risk factors, and clinical implications. Clinical Psychology Review, 18, 765794. 
Macinnes, D. L. (2006), Self-esteem and self-acceptance: an examination into their relationship and their effect on psychological health. Journal of Psychiatric and Mental Health Nursing, 13, 483-489

MacKinnon, D. P., Lockwood, C., \& Hoffman, J. (1998, June). A new method to test for mediation. Paper presented at the annual meeting of the Society for Prevention Research, Park City, Utah.

MacKinnon, D. P., Lockwood, C. M., Hoffman, J. M., West, S. G., Sheets, V. (2002). A comparison of methods to test mediation and other intervening variable effects. Psychological Methods, 7, 83-104.

Meeus, W., Iedema, J., Helsen, M., \& Vollebergh, W. (1999). Patterns of adolescent identity development: Review of literature and longitudinal analysis. Developmental Review, 19, 419-461.

National Alliance on Mental Illness. (2009). Women and Depression Factsheet. Retrieved from: http://www.nami.org/Template.cfm?Section=Women_and_Depression\&Template=/Cont entManagement/ContentDisplay.cfm\&ContentID=89194

Nolen-Hoeksema, S. (2001) Gender differences in depression. Current Directions in Psychological Science, 10 (5), 173-177.

Oosterwegel, A., Field, N., Hart, D., \& Anderson, K. (2001). The Relation of self-esteem variability to emotion variability, mood, personality traits, and depressive tendencies. Journal of Personality, 69(5), 689-708.

Orth, U., Robins, R.W., Trzesniewski, K.H., Maes, J., \& Schmi, H.M. (2009). Low self-esteem is a risk factor for depressive symptoms from young adulthood to old age. Journal of Abnormal Psychology, 118 (3), 472-478. 
Pilafova, A., Angelone, D J., \& Bledsoe, K. (2007). Physical appearance and self-esteem in college students. Psi Chi Journal of Undergraduate Research, 12, 24-31.

Pilcher, J. J., \& Walters, A. S. (1997). How sleep deprivation affects psychological variables. Journal of American College Health, 46(3), 121.

Rosenberg, M. (1965). Society and the adolescent self-image. Princeton, NJ: Princeton University Press.

Scott, J. P. R., McNaughton, L. R., \& Polman, R. C. J. (2006). Effects of sleep deprivation and exercise on cognitive, motor performance and mood. Physiology \& Behavior, 87(2), 396-408.

Spoormaker, V. I., \& van den Bout, J. (2005). Depression and anxiety complaints; relations with sleep disturbances. European Psychiatry, 20(3), 243-245.

Thacher, P. (2008). University students and "the all nighter": Correlates and patterns of students' engagement in a single night of total sleep deprivation. Behavioral Sleep Medicine, 6(1), $16-31$.

Torres, A., Zenner, C., Benson, D., Harris, S., Koberlein, T. (2007). Relationships between selfesteem and factors known to affect college attendance. Psi Chi Journal, 12

Trockel, M. T., Barnes, M. D., \& Egget, D. L. (2000). Health-related variables and academic performance among first-year college students: Implications for sleep and other behaviors. Journal of American College Health, 49(3), 125-131.

Trzesniewski, K.H., Donnellan, M.B., \& Robins, .W. (2003). Stability of self-esteem across the life span. Journal of Personality and Social Psychology, 84 (1), 205220.

Trzesniewski, K.H.R. (2004). A cohort-sequential study of self-esteem from age 25 to 
96. Dissertation Abstracts International: Section B: The Sciences and Engineering, 64(1B), 3562 .

Tsai, L \& Li, S. (2004). Sleep patterns in college students: Gender and grade differences. Journal of Psychosomatic Research, 56(2), 231-237.

Wenzlaff, R.M. \& Bates, D.E. (1998). Unmasking a cognitive vulnerability to depression: How lapses in mental control reveal depressive thinking. Journal of Personality and Social Psychology, 75, 1559-1571.

Williams, K. L., Galliher, R. V. (2006). Predicting depression and self-esteem from social connectedness, support, and competence. Journal of Social and Clinical Psychology, 25(8), 855-874

Zhang, L., \& Diao, J. (2006). A study of sleep quality and related influencing factors in college students. Chinese Journal of Clinical Psychology, 14(5), 515-517. 